\title{
Rapid and non-destructive method to assess in the vineyard grape berry anthocyanins under different seasonal and water conditions*
}

\author{
L. TUCCIO', D. REMORINI', P. PINELLI ${ }^{2}$, E. FIERINI ${ }^{2,3}$, P. TONUTTI ${ }^{4}$, G. SCALABRELLI' and G. AGATI \\ ' Department of Cultivation and Preservation of Ligneous Species 'G. Scaramuzzi', University of Pisa, Via del Borghetto \\ 80, $56 / 24$ Pisa, Italy \\ ${ }^{2}$ Department of Pharmaceutical Sciences, University of Florence, Via Ugo Schiff 6, 500 I 9, Sesto Fiorentino, Florence, Italy \\ ${ }^{3}$ Institute of Applied Physics 'N. Carrara' - CNR, Via Madonna del Piano 10, 50019 Sesto Fiorentino, Florence, Italy \\ ${ }^{4}$ Sant'Anna School of Advanced Studies of Pisa, Piazza Martiri della Libertà 33, $56 \mid 27$ Pisa, Italy \\ * Part of the present work was presented at the MACROWINE 20I0, Third International Symposium, 16-18 June 2010, \\ Torino, Italy. \\ Corresponding author: Dr Giovanni Agati, fax +39 0555225305, email g.agati@ifac.cnr.it
}

\begin{abstract}
Background and Aims: Monitoring of anthocyanins (Anth) in winegrape (Vitis vinifera L.) is fundamental for the production of top-quality red wines. This work was aimed at testing a new fluorescence-based sensor for Anth detection in the vineyard.

Significance of the Study: The present study showed a new important innovative technology for viticulture. The sensor evaluation of the large spatial and temporal heterogeneity in Anth accumulation can be useful as support parameter in the harvest date decision or for vineyard zoning of phenolic maturity.

Methods and Results: Anth in grape (cv. Aleatico) bunches attached to the vine were monitored non-destructively in the field using a fluorescence-based sensor during the 2008 and 2009 seasons and under different water regimes. The $\mathrm{ANTH}_{\mathrm{RG}}$ index $=\log \left(\right.$ far-red-fluorescence $/$ /far-red-fluorescence $\left.{ }_{\mathrm{G}}\right)$, with fluorescence signals excited with red $(\mathrm{R})$ and green $(G)$ light, was inversely correlated through an exponential function $\left(r^{2}=0.875\right)$ to the Anth concentration derived from the HPLC analysis of berry skin extracts. $\mathrm{ANTH}_{\mathrm{RG}}$ was effective in detecting the earlier ripening process in 2009 with respect to 2008 and differences in the Anth accumulation between seasons and in relation to different water regimes. Water deficit imposed in 2009 enhanced Anth concentration in berries because of a reduction in berry size but also an increase of Anth biosynthesis. This effect was observed by both destructive and $\mathrm{ANTH}_{\mathrm{RG}}$ non-destructive measurements.

Conclusions: Our results show that the employed fluorescence sensor represents a reliable, rapid and non-invasive tool for monitoring and determining Anth accumulation in situ.
\end{abstract}

Keywords: Aleatico, anthocyanin, chlorophyll fluorescence, optical sensor, phenolic maturity, ripening, Vitis vinifera L., water stress

\section{Introduction}

The use of non-destructive methods to assess fruit quality is of wide interest (Butz et al. 2005), since they represent a rapid tool for fruit sorting, evaluating storage conditions and monitoring fruit ripening. Portable sensors for fruit ripening directly applied in the field to predict the best harvest period would be particularly appealing. In viticulture, the evaluation of grape maturity is fundamental for the production of high-quality wine (Conde et al. 2007). This task is difficult because of need to consider up to three levels of maturity: technological, aromatic and phenolic maturity, which requires destructive chemical analysis (Downey et al. 2007), laboratory spectroscopic and chemometric analysis (Gishen et al. 2005) or complex sensory analysis (Le Moigne et al. 2008). Since large spatial and temporal heterogeneity in grape maturity occurs among different vineyard zones, an accurate sampling approach that is representative of the vineyard under consid- eration is needed (Bramley 2005). Considering phenolic compounds, their berry concentration depends, besides genetic factors, on specific metabolism (synthesis/degradation) and berry growth rate, both affected by cultural practices and environmental conditions, including vine water status (Kennedy et al. 2002, Ojeda et al. 2002, Downey et al. 2006, Castellarin et al. 2007a).

When water becomes a limiting factor, morphological, physiological and biochemical alterations in grape berries occur (Roby and Matthews 2004, Roby et al. 2004, Deluc et al. 2009). In general, water deficit affects more vegetative growth than carbon assimilation and carbohydrate accumulation (Matthews and Anderson 1987, Naor et al. 1994). For this reason, when leaves are expanded sufficiently and a moderate water stress not compromising their photosynthetic activity is present, the shoot growth rate decreases, resulting in a lower competition with the berry ripening process. This may induce positive effects on the 
production of aromatic and phenolic compounds (Hsiao 1973, Poni et al. 1993).

The effect of water deficit on the synthesis and concentration of phenolic compounds (flavan-3-ols, anthocyanins (Anth) and flavonols (Flav), in particular) depends on the stress level and the berry phenological stage as observed in cv. Shiraz (Ojeda et al. 2002) and Cabernet Sauvignon (Kennedy et al. 2002). Water stress is known to significantly affect size and weight of berries by a reduction of the pericarp volume rather than by a reduction of the cellular division (Ojeda et al. 2001). A moderate water deficit can lead to qualitative superior production in comparison to more favourable conditions with an optimal water supply (Düring et al. 1996, Wample and Smithyman 2002, Medrano et al. 2003, Fregoni 2005). Hence, a rational application of irrigation necessarily requires a clear understanding of the physiological responses of the vine to water stress (Cifre et al. 2005, Remorini et al. 2010) and a rapid monitoring of berry parameters. This is also of paramount importance for the characterisation of local varieties such as the cv. Aleatico studied in the present work.

Aleatico is a red-skinned variety cultivated mainly along the coastline of Tuscany and in the Elba Island (Italy) for the production of a characteristic dessert wine ('Aleatico Passito'), after partial post-harvest berry dehydration. The knowledge of morphological traits and technological features of cv. Aleatico as well as the response of this grape variety to different environmental conditions and climatic changes, including reduced rainfall and water stress, is scarce.

The development of new portable optical sensors dedicated to the non-destructive assessment of Anth in grape clusters attached to the vines represents a useful complementary tool to evaluate phenolic maturity and better characterize grapevine varieties (Agati et al. 2009, Cerovic et al. 2009, Ben Ghozlen et al. 2010a,b). The technique is based on chlorophyll fluorescence detection and the Anth screening effect on the excitation light used for the measurement: the larger the Anth concentration in the berry skin, the lower the chlorophyll fluorescence signal. This method has been validated in the laboratory by spectroscopic studies on winegrape berries (Agati et al. 2007) and whole bunches (Agati et al. 2008, Cerovic et al. 2008).

In this paper, the new optical fluorescence sensor Multiplex was used to evaluate the phenolic maturity in the Aleatico berries. The non-destructive index of Anth accumulation was followed in time, in the same vineyard, during two consecutive seasons and under different water regimes.

\section{Materials and methods}

\section{Plant material and treatments}

The experiment was conducted in two consecutive years (2008 and 2009) at the Bulichella farm, Suvereto (Livorno, Italy; $43^{\circ} 04^{\prime} \mathrm{N}, 10^{\circ} 41^{\prime} \mathrm{E}$ ) on 3-year-old (in 2008) vines of cv. Aleatico grafted on $110 \mathrm{R}$, trained to $2-3$ vertical shoots and spaced $0.6 \times 2.0 \mathrm{~m}$. Vines were planted in February 2006 in NorthSouth oriented rows.

For both trial periods, data from a nearby meteorological station were obtained from ARSIA, Tuscany Regional Agrometeorological Service. Portable data loggers (Tinytag TGU4500, Gemini, Chichester, UK) were installed at the level of irrigated and non-irrigated bunches and near the vineyard to monitor temperature and relative humidity. Evapotranspiration (ETo) was calculated by using the Blaney-Criddle's theoretical method (Brouwer and Heibloem 1986).

In 2008, the experiment lasted from 17 June to 5, September when grapes were harvested at a ${ }^{\circ}$ Brix of 27.0. Veraison occurred at the beginning of August, as determined by visual assessment of $10 \%$ berries colouring on 31 July (day of the year (DOY) 213). Water was supplied on 28 July and on 1 August by a drip irrigation system applying 46.9 and $23.4 \mathrm{~L}$ water per plant, respectively. A main rain event (40 mm) occurred on 15 August (DOY 228). In 2009, two treatments were applied: non-irrigated (water stress, WS) and irrigated (IR). The WS plants were also covered at soil level by plastic transparent sheets to avoid rain infiltration. The experiment was carried out from 8 July to 1 , September when grapes were harvested at a ${ }^{\circ}$ Brix of 25.8 . Veraison occurred at the end of July ( $10 \%$ of berries colouring on 22, July DOY 203). Water was supplied on 20 July and on 15 August applying 67.5 and $22.5 \mathrm{~L}$ of water per plant, respectively. A main rain event (20 mm) occurred on 4 August (DOY 216).

\section{Physiological responses}

From the beginning of the experiment, the water potential and gas exchange plant physiological indicators were used to evaluate vine performances and water deficiency status. Midday stem water potential $\left(\mathrm{MD} \Psi_{\mathrm{s}}\right)$ was measured once a week using a pressure chamber on three non-transpiring leaves, from three different plants, that had been bagged with aluminium foil for 1 hour before measurements. Photosynthetic rate (Pn) and stomatal conductance (gs) were measured once a week on 15 vines per treatment, one leaf per vine, using a portable gas exchange system (Li-Cor 6400, Li-Cor Inc., Lincoln, NE, USA) from preveraison to complete ripening. The gs was calculated according to the LiCor 6400 manual. Measurements were performed in the morning from 09:00 to 10:30 h.

\section{The fluorimetric sensor}

To measure phenolic maturity, 60 (in 2008) and 50 (in 2009) different bunches distributed on four adjacent rows were marked and measured by the fluorimetric sensor once a week from veraison to harvest, directly on the vines.

The Multiplex 2 (Mx; FORCE-A, Orsay, France) was a handheld battery-operated optical sensor consisting of four excitation light-emitting diode (LED) sources in the UV-A $(370 \mathrm{~nm})$, blue $(460 \mathrm{~nm})$, green $(516 \mathrm{~nm})$ and red $(637 \mathrm{~nm})$ and three detection channels in the blue-green, red and far-red spectral regions. These two last detection bands at 680-690 nm (red fluorescence, RF) and 730-780 nm (far-red fluorescence, FRF), respectively, corresponded to the two emission peaks of chlorophyll (Cerovic et al. 1999). Being the LED sources pulsed and synchronized to detection, the sensor was insensitive to ambient light and could be used directly in the vineyard. The large detection area of the sensor ( 8 -cm diameter) permitted a signal to be acquired from a large area of each cluster. Acquisition time for a single bunch sample was $1 \mathrm{~s}$. The collected data were visible on a real-time display and stored on a secure digital card for further analysis. Different combinations of the red (RF) and far-red (FRF) fluorescence signals at the various excitation bands could be used as indices of different compounds, such as Flav, Anth and chlorophyll $(\mathrm{Chl})$. Considering the fluorescence signals $R F_{R}$ and $F R F_{R}$, excited with red (R) light, and $F R F_{G}$ and FRF $_{U V}$, excited with green $(\mathrm{G})$ and ultraviolet (UV) radiation, respectively, we can define two Anth indices:

$$
\mathrm{ANTH}_{\mathrm{RG}}=\log \left(\mathrm{FRF}_{\mathrm{R}} / \mathrm{FRF}_{\mathrm{G}}\right)
$$

and

$$
\mathrm{ANTH}_{\mathrm{R}}=\log \left(5000 / \mathrm{FRF}_{\mathrm{R}}\right),
$$

the Flav index 


$$
\mathrm{FLAV}=\log \left(\mathrm{FRF}_{\mathrm{R}} / \mathrm{FRF}_{\mathrm{UV}}\right),
$$

and the $\mathrm{Chl}$ index

$$
\mathrm{CHL}=\mathrm{FRF}_{\mathrm{R}} / \mathrm{RF}_{\mathrm{R}}
$$

The choice of these equations is based on previous spectroscopic studies (Cerovic et al. 2002, Agati et al. 2007) and on the optical properties of chlorophyll and Flav. Briefly, the intensity of Chl fluorescence depends on the excitation light reaching the $\mathrm{Chl}$ layer inside the berries. It is therefore reduced by Anth localized into the outer skin layers, which absorb part of the excitation light. The higher the Anth concentration, the lower the Chl fluorescence signal. The attenuation is also depending on the excitation wavelength, according to its overlapping with the absorption spectrum of Anth, and therefore it will be higher at the peak (at around $520 \mathrm{~nm}$ ) than in the tail in the red of the Anth absorption band. The definition of the Anth index given in Eqn 1, by comparing the Chl fluorescence intensity under $\mathrm{G}$ and $\mathrm{R}$ lights, represents a differential absorption measurement (in accordance with the Beer-Lambert's law) that is proportional to the Anth content. The same above consideration applies in the case of Flav, with G light replaced by UV radiation, in order to explain the origin of the FLAV index defined by Eqn 3.

The use of the single $\mathrm{FRF}_{\mathrm{R}}$ signal under R light in Eqn 2 relies on a sufficiently significant absorption of Anth at $637 \mathrm{~nm}$. The 5000 value in Eqn 2 represented the full-scale value in $\mathrm{mV}$ of photodiodes. The ANTH $\mathrm{RG}_{\mathrm{R}}$ and FLAV indices were corrected for differences in the $R$ versus $G$ and $R$ versus UV LED light intensities, respectively, using a fluorescence standard film (FORCE-A) with known absorption properties.

The CHL index (Eqn 4) is based on the partial reabsorption of RF, depending on the Chl concentration (Buschmann 2007), and on the absence of reabsorption on the FRF band. Consequently, the CHL index increases with the increase of Chl concentration.

\section{Berry sampling and destructive measurements}

In order to calibrate the $\mathrm{Mx}$ sensor for the Anth and Flav content, for each date during the 2008 season, three different bunches per cultivar were randomly sampled. Fourteen berries from the exposed side of each bunch were collected, measured by the Mx, weighted and frozen for subsequent extraction and high-performance liquid chromatography (HPLC) quantification of phenolic compounds.

The skin from the upper half (flower scar face) of 14 berries was peeled off and ground under liquid nitrogen. The resulting skin powder was transferred to $3 \mathrm{~mL}$ of acidified extraction solvent $\left(70 \% \mathrm{EtOH}, 25 \% \mathrm{H}_{2} \mathrm{O}, 5 \%\right.$ formic acid), maintained under stirring in the dark for $1 \mathrm{~h}$ and then centrifuged for $3 \mathrm{~min}$ at $4100 \times g$. The pellet was re-extracted twice using the same procedure, and the final three pooled supernatants were adjusted precisely to $10 \mathrm{~mL}$. The whole procedure was performed at room temperature $\left(20-25^{\circ} \mathrm{C}\right)$. Extracted samples were stored at $-20^{\circ} \mathrm{C}$ until HPLC analysis.

For both seasons, a set of 200 berries was randomly collected weekly from the beginning of veraison to harvest and processed for Anth extraction within the same day. For each sampling, 60 berries were randomly chosen, divided into three groups of 20 berries, which were used as triplicates, and processed according to the method of Di Stefano et al. (2008) slightly modified as follows. Berry skins of each replicate were manually separated from pulp and seeds, weighed and extracted for $4 \mathrm{~h}$ at $25^{\circ} \mathrm{C}$ in $25 \mathrm{~mL}$ of a pH 3.2 tartaric buffer solution. This solution contained
$12 \%(\mathrm{v} / \mathrm{v})$ ethanol, $2 \mathrm{~g} / \mathrm{L}$ sodium metabisulphite, $5 \mathrm{~g} / \mathrm{L}$ tartaric acid and $22 \mathrm{~mL} / \mathrm{L} \mathrm{NaOH} 1 \mathrm{~N}$. After grounding in a mortar and pestle, the extract was separated by centrifugation for $10 \mathrm{~min}$ at $3000 \mathrm{rpm}$. The pellet was re-suspended in $20 \mathrm{~mL}$ of buffer and centrifuged for $5 \mathrm{~min}$. The final two pooled supernatants were adjusted precisely to $50 \mathrm{~mL}$ with the buffer solution, diluted (1:20) with ethanol : water : $\mathrm{HCl}(70: 30: 1)$ and measured spectrophotometrically at $540 \mathrm{~nm}$. Anth were expressed as mg of equivalents of malvidin 3-O-glucoside. Remaining berries (140) were used to determine the concentration of total soluble solids ( ${ }^{\circ}$ Brix) by a digital refractometer (Model 5301 l, TR, Forlì, Italy), the $\mathrm{pH}$ by a bench $\mathrm{pH}$-meter (Hanna Instruments, Milano, Italy) and total acidity by titration with $\mathrm{NaOH} 0.1 \mathrm{~N}$.

\section{HPLC/DAD analysis}

HPLC/DAD analyses were performed on a HP 1100L liquid chromatograph equipped with a Diode Array Detector (DAD) detector and managed by an HP Chemstation software (Agilent Technologies, Palo Alto, CA, USA). Hydroxycinnamic acids and flavonoids were separated using a $4.6 \times 250 \mathrm{~mm}$ Polaris E $\mathrm{RP}_{18}$ $(5 \mu \mathrm{m})$ column (Varian, Darmstadt, Germany) operating at $27 \pm 0.5^{\circ} \mathrm{C}$. The eluent was $\mathrm{H}_{2} \mathrm{O}$ (adjusted to $\mathrm{pH} 3.2$ by $\mathrm{HCOOH} / \mathrm{CH}_{3} \mathrm{CN}$. A four-step linear gradient solvent system was used, starting from $100 \% \mathrm{H}_{2} \mathrm{O}$ to $100 \% \mathrm{CH}_{3} \mathrm{CN}$ during a 53 -min period, at the flow rate of $0.8 \mathrm{~mL} / \mathrm{min}$ as previously reported (Saracini et al. 2005). Anth were separated using a RP-80 C12 column (Phenomenex Synergi Max), $150 \times 3 \mathrm{~mm}, 4 \mu$ (Phenomenex, Torrance, CA, USA) operating at $27 \pm 0.5^{\circ} \mathrm{C}$. The eluent was $\mathrm{H}_{2} \mathrm{O}$ (adjusted to $\mathrm{pH} 2.0$ by $\mathrm{HCOOH}$ ) $/ \mathrm{CH}_{3} \mathrm{CN}$. A four-step linear gradient solvent system, at the flow rate of $0.4 \mathrm{~mL} / \mathrm{min}$ for $28 \mathrm{~min}$, was used (Mulinacci et al. 2008).

\section{HPLC/MS analysis}

HPLC/Mass Spectrometry (MS) analyses were performed using the same analytical conditions of HPLC/DAD analysis. In detail, the HPLC/DAD was interfaced with a HP 1100 MSD APIelectrospray (Agilent Technologies) operating in negative and positive ionization mode under the following conditions: nitrogen gas temperature $350^{\circ} \mathrm{C}$, nitrogen flow rate $10 \mathrm{~L} / \mathrm{min}$, nebuliser pressure $30 \mathrm{psi}$, quadrupole temperature $30^{\circ} \mathrm{C}$, capillary voltage $3500 \mathrm{~V}$. The mass spectrometer operated at $120 \mathrm{eV}$ of negative fragmentor for flavonoid and caffeic derivatives, and at $120 \mathrm{eV}$ positive fragmentor for Anth.

\section{Quantitative analysis}

Identification of individual phenolics was carried out using their HPLC retention times, and both UV/Vis and MS spectra. Quantification of the single phenolic compounds was directly performed by HPLC/DAD using a five-point regression curve built with the available standards. Curves with a coefficient of determination $r^{2}>0.998$ were considered. In particular, hydroxycinnamic acids amounts were calculated at $330 \mathrm{~nm}$ using caffeic acid as reference. Quercetin and kaempferol glycosides were calibrated at $350 \mathrm{~nm}$ using quercetin 3-O-rutinoside and kaempferol 3-O-rutinoside, respectively. Finally, Anth glycosides were calibrated at $520 \mathrm{~nm}$ using malvidin 3-O-glucoside (oenin) as reference. The molecular weight correction has been performed if necessary. Compound concentrations were expressed as $\mathrm{mg} / \mathrm{g}$ of skin fresh weight or as $\mu \mathrm{g}$ per $\mathrm{cm}^{2}$ of berry surface.

\section{Statistical analysis}

Statistical analysis was carried out with SigmaPlot for Windows Version 11.0 (Systat Software, Inc., Erkrath, Germany) and statistical differences between treatments were analysed by 
one-way analysis of variance (ANOVA). Results are given as means \pm standard deviation (SD).

\section{Results and discussion}

\section{Phenolic compound characterization of Aleatico berries}

The main anthocyanosides detected in Aleatico berry skin were (i) the 3-O-glucosides of delphinidin, cyanidin, petunidin, peonidin and malvidin; (ii) the 3-O-acetylglucosides of delfinidin, petunidin and malvidin; and (iii) the 3-O-p-cumaroylglucosides of petunidin and malvidin. Cyanidin and peonidin 3-Oacetylglucosides, and delphinidin, cyanidin and peonidin 3-O-pcumaroylglucosides were also presents in lower amounts.

Among Flav, quercetin and kaempferol glycosides were detected, with quercetin 3-O-glucuronide, quercetin 3-Orutinoside, quercetin 3-O-glucoside as the main compounds. Kaempferol 3-O-glucuronide, kaempferol 3-O-rutinoside, and kaempferol 3-O-glucoside were present as minor compounds.

Among hydroxycinnamic acids, caffeoyl-tartaric acid and p-cumaroyl tartaric acid were identified.

Total amounts of the three classes of phenolic compounds, hydroxycinnamic acids (HCA), Flav and Anth, were calculated as the sum of concentrations expressed as $\mathrm{mg} / \mathrm{g}$ of skin fresh weight of the compounds identified for each class. The time evolution of HCA, Flav and Anth concentration (mg/g of skin fresh weight $(\mathrm{FW})$ ) is represented in Figure la for the samples collected in 2008. Anth started to increase at DOY 213 (onset of veraison). Flav increased over the two first sampling dates and then remained somewhat constant. If expressed in terms of concentration per berry (Figure lb), Flav followed a two-step increase separated by a lag phase; in fact, they increased up to the onset of veraison and then increased again towards the end of the developmental cycle. This trend is similar to that previously observed in the Shiraz berries, where a late increase in the expression of the gene encoding the flavonol synthase was observed (Downey et al. 2003). The rise in Anth biosynthesis appeared to be shifted in time with respect to Flav: this could be due to the competition for the common substrate, dihydroflavonols, between flavonol synthase and dihydroflavonol 4-reductase (Davies et al. 2003, Jaakola et al. 2004). The concentration of HCA remained almost unchanged during the investigated period (Figure 1).

\section{Multiplex index calibration}

Comparing the non-destructive ANTH indices with the related Anth contents from the destructive HPLC analysis, we found that the best correlation was obtained between the compound concentration expressed on a surface basis and the $\mathrm{ANTH}_{\mathrm{RG}}$ index (Figure 2a). Here, only samples from complete veraison to harvest were considered. The $\mathrm{ANTH}_{\mathrm{RG}}$ index was inversely correlated with the Anth surface concentration. The best fitting of data was obtained with an exponential function:

$$
\mathrm{ANTH}_{\mathrm{RG}}=0.27+1.253 \cdot \exp (- \text { Anth / 97.94) }
$$

giving a coefficient of determination, $\mathrm{r}^{2}$, of 0.875 (Figure 2a). Yet, a linear regression $\left(\mathrm{ANTH}_{\mathrm{RG}}=1.114-0.00371 \cdot \mathrm{Anth}\right)$ can be appropriate as well $\left(\mathrm{r}^{2}=0.856\right)$.

In Figure $2 b$, the concentrations of Flav expressed as $\mu \mathrm{g}$ per $\mathrm{cm}^{2}$ of berry surface are compared with the Multiplex nondestructive FLAV index. In this case, the FLAV index was completely uncorrelated to the Flav berry skin content. Our analysis show that while the $\mathrm{ANTH}_{\mathrm{RG}}$ index can be used to predict the Anth content in grape skin, the FLAV index cannot be considered a good proxy of Flav content, as explained below.
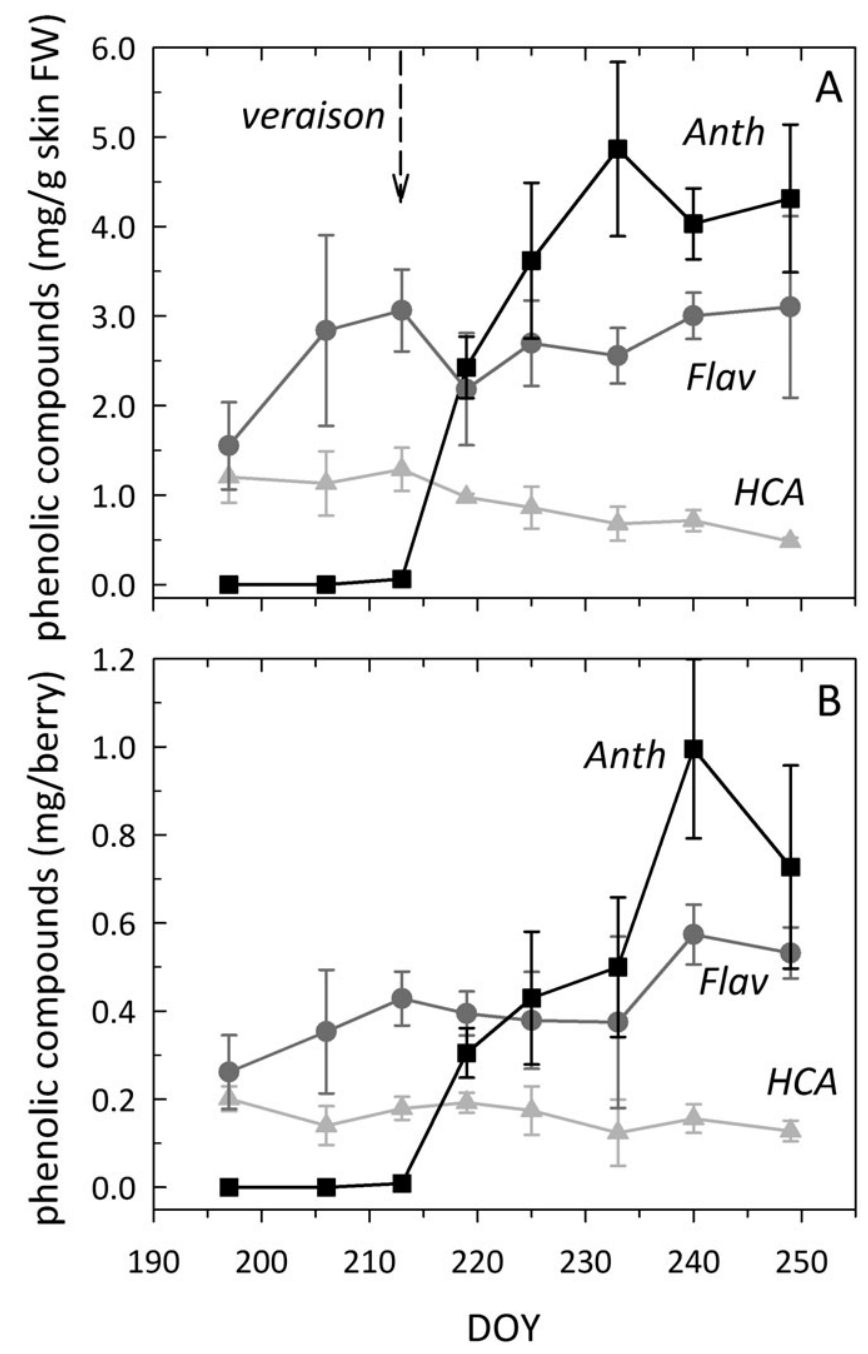

Figure 1. Time evolution of the hydroxycinnamic acid (HCA), flavonols (Flav) and anthocyanins (Anth) content determined by HPLC/ $\mathrm{DAD}$ analysis in Aleatico berry skin extracts from the 2008 trial. The arrow indicates the beginning of veraison ( $10 \%$ of berries colouring). Values are the mean $( \pm S D)$ of three bunch samples (14 half-berries per bunch) for each date and expressed as $\mathrm{mg} / \mathrm{g}$ of skin fresh weight (A) or as mg per single berry (B).

\section{Comparison of 2008 and 2009 seasons}

The climatic parameters of the 2008 and 2009 seasons in the area where the experiments were carried out were recorded (see online Supporting Information). The global irradiance was higher (25\% as average) in 2009 in comparison with 2008. Relative humidity was similar for the two seasons, ranging between 40 and $80 \%$. The air temperature frequently exceeded $28^{\circ} \mathrm{C}$ in 2008 , while in 2009 , this occurred mainly during the second part of the season (Figure S1, online Supporting Information). ETo and precipitation for the two experimental periods were analogous, with an average of $125 \mathrm{~mm}$ of rain during the pre-veraison phase of both seasons (Figure S2, online Supporting Information). Relative humidity and air temperature recorded by the Tinytag datalogger (located in the vineyard) did not markedly differ from those collected by the meteorological station (data not shown).

The climatic conditions and water supply affected the midday stem water potential (Figure 3a) and the gas exchange parameters (Figure 3b,c) that reached lower values in 2009 than in 2008, comparing the irrigated vines. In particular, the 2008 photosynthetic activity (Figure $3 \mathrm{~b}$ ) and conductance of leaves 

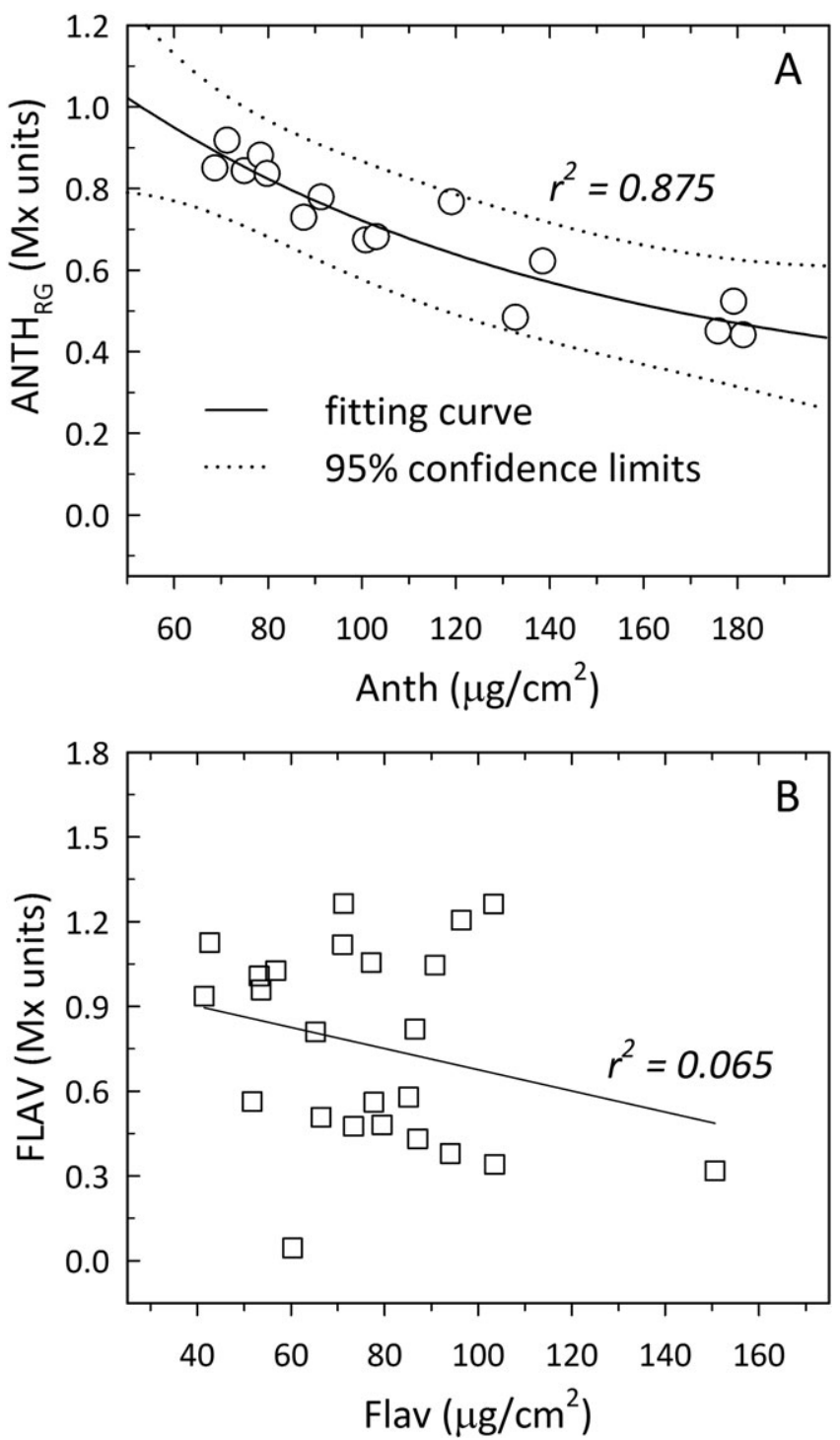

Figure 2. Relationship between the $\operatorname{ANTH}_{R G}(\mathrm{~A})$ and FLAV (B) indices measured in lab by the Multiplex sensor and the surfacebased concentration in berry skin of Anth and Flav, respectively, as determined by HPLC.

(Figure 3c) increased during veraison and maintained higher values than in 2009 (IR treatment). During 2009, both parameters were decreasing, apart from the partial recovery because of water supply on DOY 227. These data indicate that the vines experienced more pronounced stress conditions in 2009 than in the 2008 season. This may be the reason for the differences in berry development and Anth concentration observed at harvest between the two seasons (see Table 1). The Anth in 2009 expressed as $\mathrm{g} / \mathrm{kg}$ of berries were $8 \%$ higher than in 2008 . The difference reached $26 \%$ when Anth were expressed in mg/g of skin, because of the marked difference in skin fresh weight.

The time evolution of technological maturity, as indicated by the maturity index $\left({ }^{\circ} \mathrm{Brix} \bullet \mathrm{pH}\right.$; Van Rooyen et al. 1984) reported in Figure $4 \mathrm{a}$, as well as the evolution of berry fresh weight (Figure $4 \mathrm{~b}$ ) and the onset of veraison clearly indicated that a delayed berry ripening process occurred in 2008. Such evidence was confirmed by the results of the non-destructive in field measurements using the Mx optical sensor.

The time course of the Anth indices derived by the $\mathrm{Mx}$ measurements in situ showed that in both seasons (2008 and 2009), the $\mathrm{ANTH}_{\mathrm{R}}$ index increased exponentially starting from
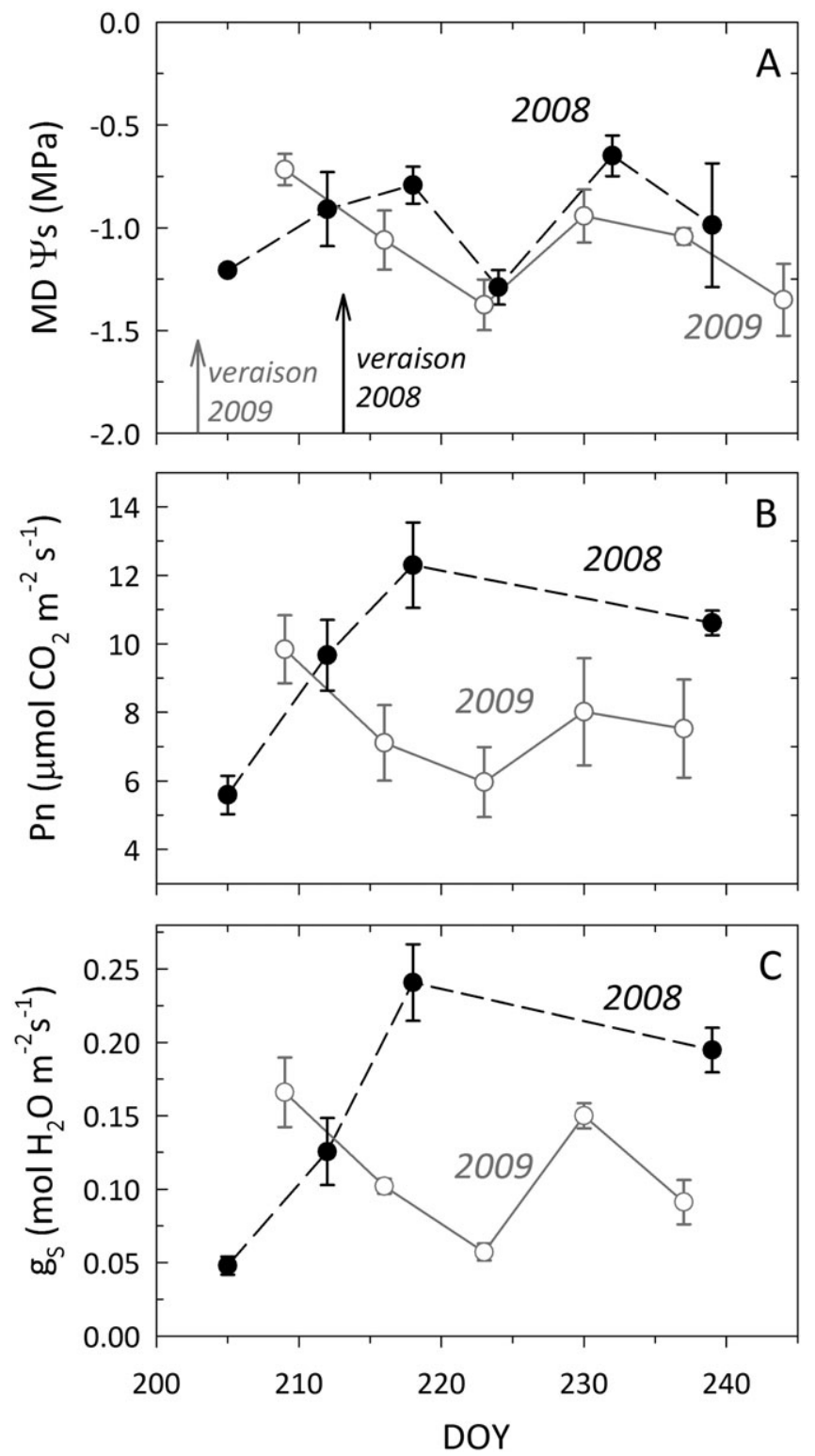

Figure 3. Changes in midday stem water potential $(A)$, photosynthetic rate $(B)$ and stomatal conductance $(C)$ of Aleatico plants during the 2008 and 2009 seasons. 2009 data refer to the irrigated vine (IR) treatment. Arrows in $(A)$ show the onset of veraison. Water potential values are the average of three replicates. Gas exchange data come from the average of 15 leaf samples measured between 9:00 and 10:30 a.m. Error bars represent the standard deviations.

Table 1. Anthocyanin concentration and weight of Aleatico berries at harvest for the 2008 and 2009 consecutive seasons for irrigated vines.

\begin{tabular}{lcc}
\hline & \multicolumn{2}{c}{ Season } \\
\cline { 2 - 3 } & $\mathbf{2 0 0 8}$ & $\mathbf{2 0 0 9}$ \\
\hline Berry weight $(\mathrm{g}$ FW) & $1.382 \pm 0.021^{\mathrm{a}}$ & $1.426 \pm 0.101^{\mathrm{a}}$ \\
Berry skin weight $(\mathrm{g} \mathrm{FW})$ & $0.253 \pm 0.030^{\mathrm{a}}$ & $0.206 \pm 0.030^{\mathrm{b}}$ \\
Anth $(\mathrm{mg} / \mathrm{g}$ skin FW) & $2.962 \pm 0.248^{\mathrm{b}}$ & $3.736 \pm 0.188^{\mathrm{a}}$ \\
Anth $(\mathrm{mg} / \mathrm{kg})$ & $498 \pm 3^{\mathrm{b}}$ & $538 \pm 10^{\mathrm{a}}$ \\
\hline
\end{tabular}

Values with different letters are significantly different at $P<0.05$. Data are the average $( \pm S D)$ of three replicates. Anth are expressed as weight of malvidin 3-O-glucoside equivalents. Anth, anthocyanins; FW, fresh weight. 
veraison (Figure 5a). On the other hand, the $\mathrm{ANTH}_{\mathrm{RG}}$ showed a biphasic behaviour, increasing during the initial accumulation of Anth, reaching a peak at full veraison $(100 \%$ of berries colouring) and decreasing thereafter until harvest (Figure 5b).
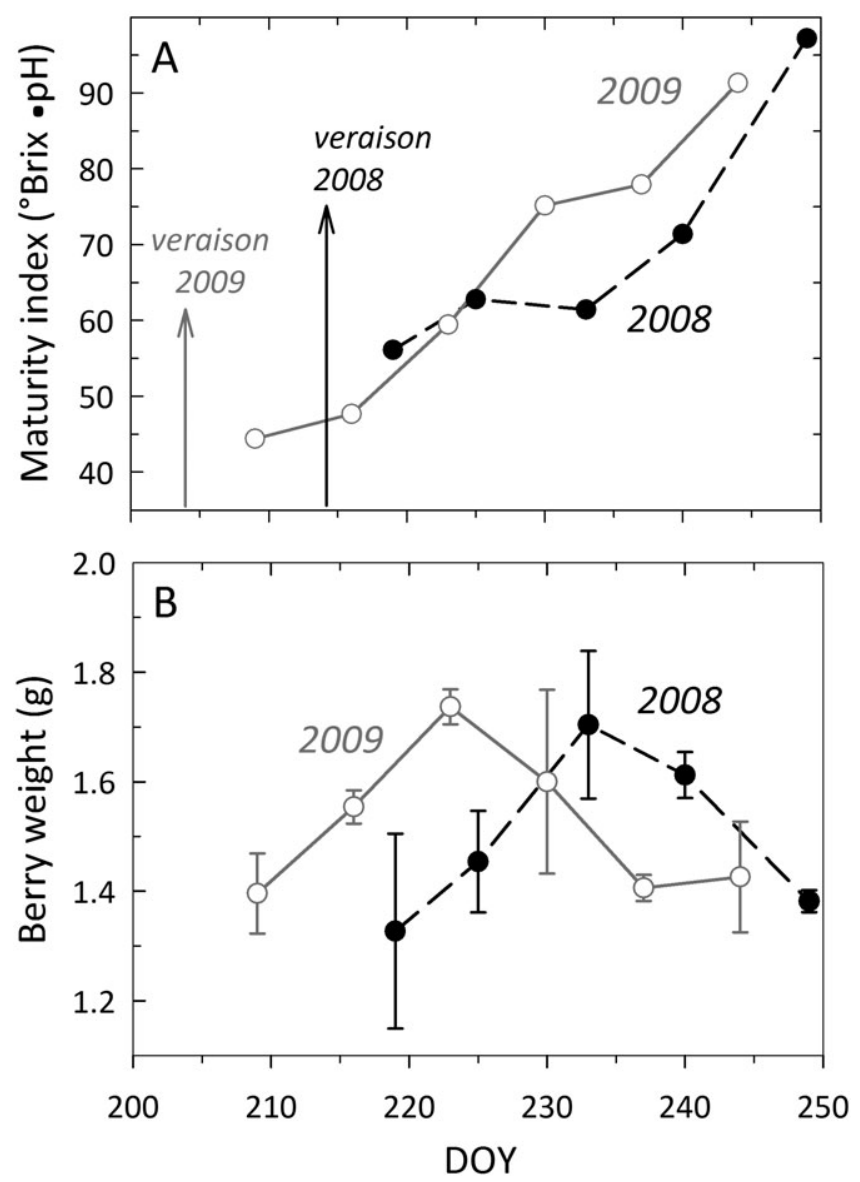

Figure 4. Time course of the ${ }^{\circ} \mathrm{Brix} \bullet \mathrm{pH}$ maturity index $(\mathrm{A})$ and mean berry fresh weight (B) of Aleatico berries for the 2008 and 2009 seasons. 2009 data refer to the irrigated vine (IR) treatment. Arrows in $(A)$ show the onset of veraison. Values are the average of three replicates; error bars in (B) represent the standard deviations.
The FLAV index decreased with time from veraison to harvest (Figure 5c), while the CHL index was linearly decreasing over the whole ripening period (Figure $5 \mathrm{~d}$ ).

By comparing the time course of the 2008 and $2009 \mathrm{Mx}$ indices, it is evident that berry ripening resulted anticipated in 2009 , in agreement with phenological data (onset of veraison) and harvesting dates for the two seasons.

The biphasic behaviour of $\mathrm{ANTH}_{\mathrm{RG}}$ can be explained by considering the difference in the absorption properties of Anth at the two excitation wavelengths in the green $(516 \mathrm{~nm})$ and in the red $(637 \mathrm{~nm})$. With increasing Anth concentration, i.e. with increasing DOY, both $\mathrm{FRF}_{\mathrm{G}}$ and $\mathrm{FRF}_{\mathrm{R}}$ signals will decrease, because of an increased screening effect on Chl, but the latter with a lower rate because of the lower absorptivity of Anth in the red. Applying the logarithmic function of Eqn 1 to calculate the time course of $\mathrm{ANTH}_{\mathrm{RG}}$, according to the Beer-Lambert's law, results in the difference of two components that increase exponentially with time but with different rate constants (see also Ben Ghozlen et al. 2010a). Consequently, an initial increase in the index is followed by a decrease. Once the maximum has been reached, $\mathrm{ANTH}_{\mathrm{RG}}$ is expected to be inversely correlated to the Anth content. Therefore, the larger values in $\mathrm{ANTH}_{\mathrm{RG}}$ recorded at harvest for 2008 with respect to 2009 suggested a higher accumulation of Anth in the latter season. This was confirmed by the destructive analysis of berry samples as showed in Table 1 .

The sharp decrease of FLAV starting at DOY 213 (Figure 5c) is in contrast with the time course of Flav resulting from the HPLC analysis (Figure 1). This was not unexpected because of the absence of correlation between the Mx FLAV index and the Flav concentration (Figure 2b). It is because of the accumulation of Anth, which largely affects the $\mathrm{FRF}_{\mathrm{R}}$ signal, while the FRF $_{\text {Uv }}$ was changed slightly. Consequently, according to their definition (Eqn 1 and 2), the FLAV index becomes similar to the inverse of the $\mathrm{ANTH}_{\mathrm{R}}$ index (FLAV $\propto-\mathrm{ANTH}_{\mathrm{R}}$ ), as seen comparing Figure $5 \mathrm{a}$ and $\mathrm{b}$. The same decrease with time in FLAV was previously observed in cvs. Pinot Noir and Pinot Meunier, while an increase in FLAV with time was found for the Anth-free cv. Chardonnay (Ben Ghozlen et al. 2010b).

\section{Water status effects}

The $\mathrm{ANTH}_{\mathrm{RG}}$ index measured in the field was used to compare the effect of vine water status on Anth accumulation in berries during the 2009 season. The vine physiological response to the
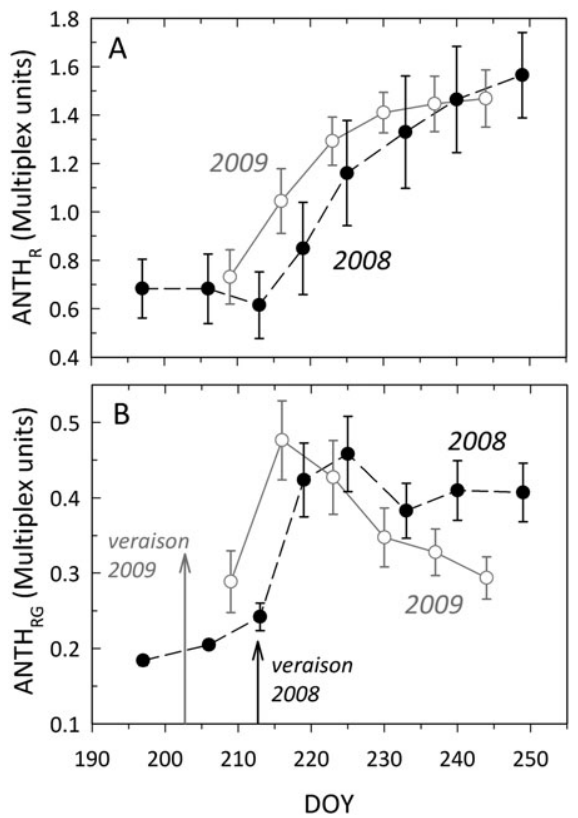

DOY

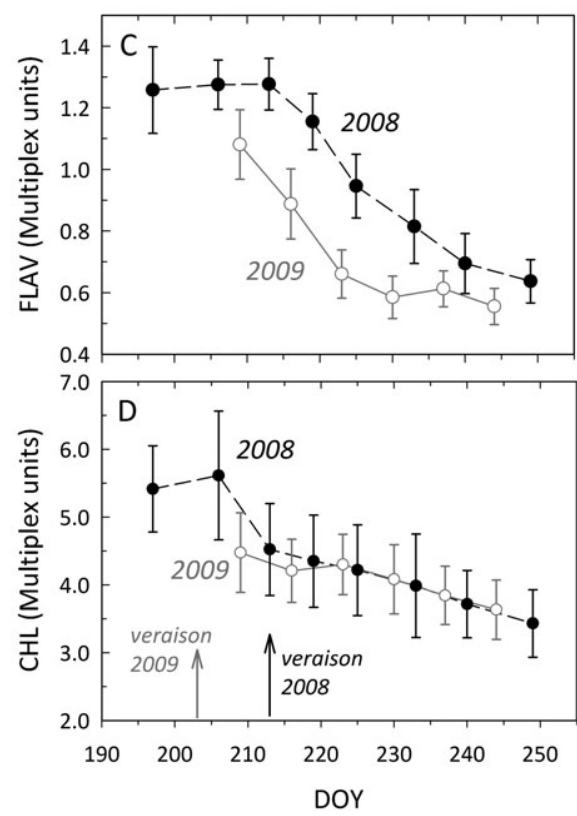

() 2011 Australian Society of Viticulture and Oenology Inc.
Figure 5. Time course of the anthocyanin (A, B), flavonol (C) and chlorophyll (D) indices measured in situ on Aleatico clusters by the Multiplex sensor. Arrows in $(B, D)$ show the onset of veraison. Values are the average $( \pm S D)$ over 60 and 50 bunches for the 2008 and 2009 season, respectively. See text for definition of ANTH $_{R}$, ANTH $_{\text {RG, FLAV and CHL }}$ indices. 

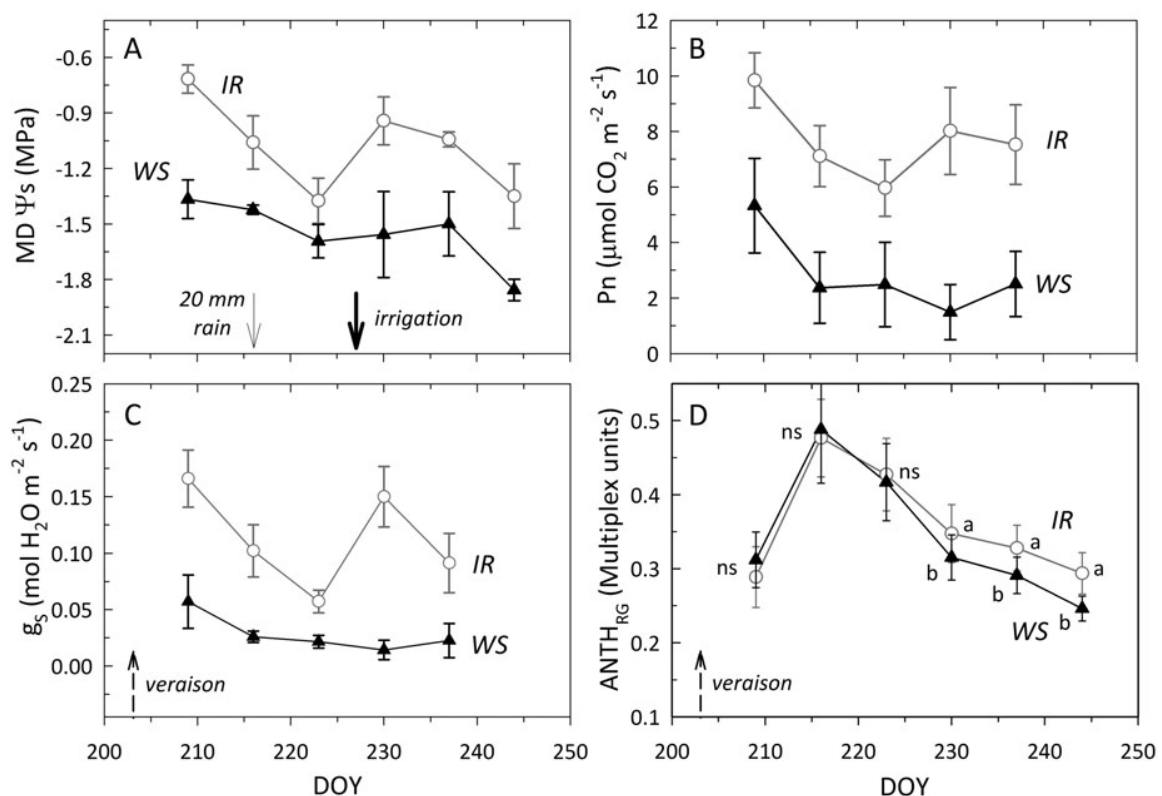

Figure 6. Time course of midday stem water potential (A), photosynthetic rate (B), stomatal conductance (C) and the ANTH $\mathrm{RG}_{\mathrm{R}}$ index measured in situ by the Multiplex sensor for irrigated (IR, circles) and non-irrigated (WS, triangles) plants during the 2009 season. IR data are the same

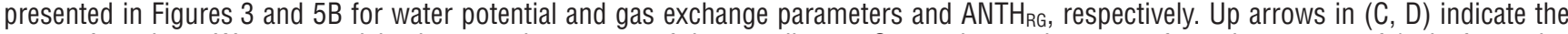
onset of veraison. Water potential values are the average of three replicates. Gas exchange data come from the average of 15 leaf samples measured between 9:00 and 10:30 a.m. ANTH ${ }_{\mathrm{RG}}$ values are the average over 50 bunches. Error bars represent the standard deviations. Arrows in $(A)$ indicate a rain event (thin line) and water supply (thick line). Values with different letters indicate significance at $P<0.05$; ns $=$ not significant.
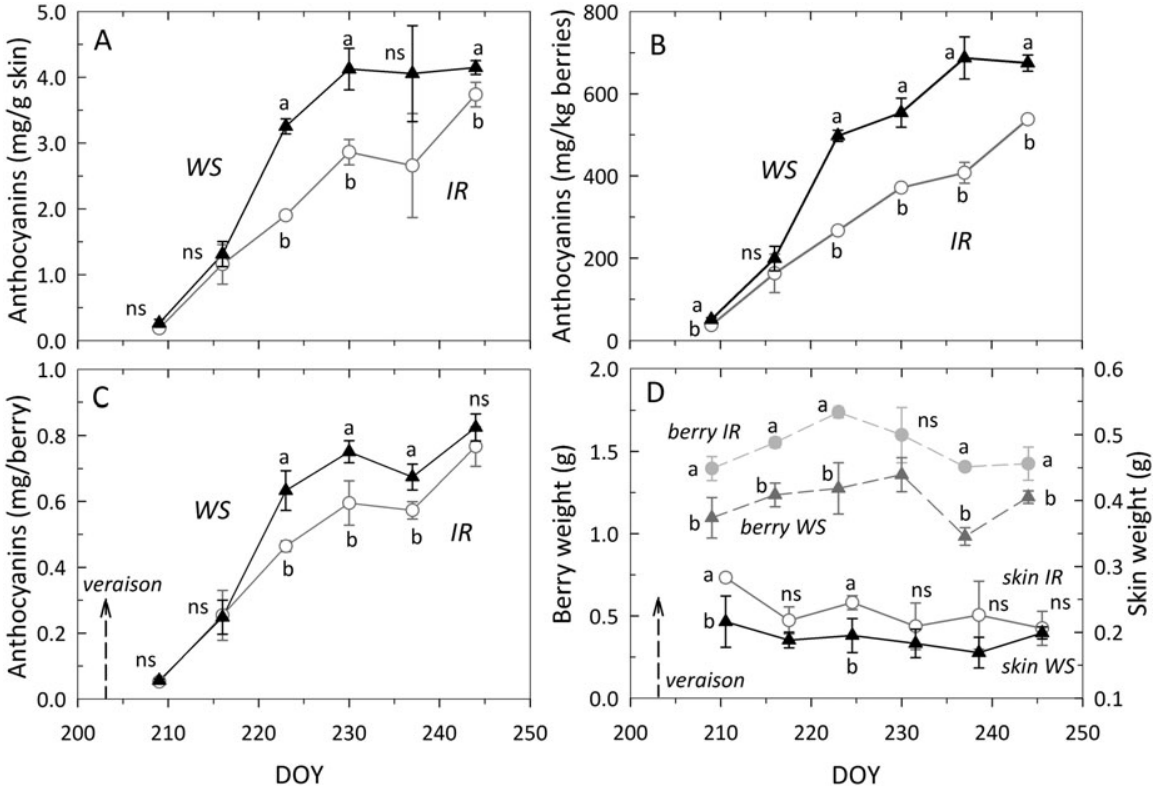

Figure 7. Time evolution of total anthocyanins measured in lab and expressed as $\mathrm{mg} / \mathrm{g}$ of skin fresh weight $(A), \mathrm{mg} / \mathrm{kg}$ of berries (B), mg per berry (C) and of berry and skin weight (D) of irrigated (IR, circles) and non-irrigated (WS, triangles) plants during the 2009 season. Arrows in $(C, D)$ indicate the onset of veraison. Each point results from the average of three replicates. Error bars represent the standard deviations; values with different letters indicate significance at $P<0.05 ;$ ns $=$ not significant . two irrigation regimes is represented by the temporal evolution of the midday stem water potential (Figure 6a), photosynthetic rate (Figure 6b) and stomatal conductance (Figure 6c). These physiological indicators revealed that the water stress in nonirrigated (WS) plants was already intense at veraison and increased thereafter. WS conditions determined a decrease of stem water potential to values lower than -1.4 MPa (Figure 6a), whereas under IR treatment, these levels were registered only for short periods. Values of Pn (Figure 6b) and gs (Figure 6c) were markedly different between the two applied water regimes during the whole season.

The accumulation of Anth determined by the $\mathrm{ANTH}_{\mathrm{RG}}$ index for the two water regimes (Figure 6d) showed that the time evolution of $\mathrm{ANTH}_{\mathrm{RG}}$ Was similar for IR and WS vines; however, starting from DOY 230, the index values for stressed plants were significantly $(P<0.05)$ lower than those of plants under IR, indicating a higher accumulation of Anth under water-stressed condition. This difference in the Anth content between the two samples was increasing with ripening $(P=0.015$ at DOY 237 and $P<0.001$ at DOY 244).

The larger content of Anth in bunches of the WS vines as compared with IR samples was confirmed by the destructive analysis (Figure 7). The Anth concentration in WS samples started to increase more markedly than in IR berries after DOY 216 (Figure 7a,b). The divergence increased with time and then partially attenuated towards harvest. Since both total berry and skin weights in stressed plants were significantly lower than watered plants (Figure 7d), it is clear that a 
concentration (dilution) effect was present in the Anth values expressed as weight per $\mathrm{g}$ of skin or $\mathrm{kg}$ of berries. However, when Anth were expressed on a per berry basis (Figure 7c), there was still a marked difference in the Anth content in favour of the WS samples, by up to $36 \%$. On the other hand, the mean increase of Anth concentration as $\mathrm{mg} / \mathrm{kg}$ of berries of about $57 \%$ from DOY 223 to harvest in the WS samples with respect to IR samples cannot be accounted for by the $21 \%$ mean reduction of berry mass induced by water deficit. Analogously, the $45 \%$ average higher Anth content expressed as mg per skin fresh weight in WS versus IR treatments cannot be explained by the $16 \%$ average difference in skin berry weight. Our results were similar to those observed when water deficit was imposed to Cabernet Sauvignon vines (Castellarin et al. 2007a).

The attenuation in the difference in Anth between the two water treatments observed at the end of the experimentation can be explained as being due to a shift in the ripening processes. Maturity was accelerated by WS (Castellarin et al. 2007a); therefore, WS berries reached the highest Anth content earlier than IR samples. Furthermore, the marked stress conditions imposed ( $\mathrm{MD} \Psi_{\mathrm{s}}<-1.8 \mathrm{MPa}$ ) could result in an increased structural complexity of phenolic compounds in the berry (i.e. higher degree of polymerization) leading to a lower Anth extractability (Sivilotti et al. 2005).

Our results confirm previous observations that, in different varieties, WS increases Anth accumulation in berries as a result of a reduced berry size and a stimulation of Anth biosynthesis (Ojeda et al. 2002, Acevedo et al. 2004, Castellarin et al. 2007a,b, Chalmers et al. 2008, Peterlunger et al. 2010).

\section{Conclusions}

We have showed that the Mx fluorescence sensor was able to monitor the time evolution of Anth accumulation directly in the vineyard. It represents a rapid and non-invasive tool to compare the effect of different vineyard managements, soil and environmental factors on grape phenolic maturity. Using an appropriate calibration curve for the Mx indices, obtained by comparison between non-destructive measurements and destructive Anth analyses on the largest range of Anth concentrations, the Anth content, expressed as $\mathrm{g} / \mathrm{kg}$ of grape, in different vineyard blocks can be predicted. The sensor cannot provide, at the moment, indices of Flav content in red winegrape because of the covering effect of Anth. However, it can be applied to white grapes where the FLAV index dynamics may represent a new useful parameter to follow maturity (Lenk et al. 2007).

The capacity to retrieve non-invasively at the same time, multiple parameters is an attractive advantage of the $\mathrm{Mx}$ sensor. Beside the information on the Anth content, the degradation of $\mathrm{Chl}$ can be followed simultaneously on the same samples (Figure 5d). The Chl fluorescence decrease during grape berry ripening was proved to be inversely correlated to sugar concentration (Kolb et al. 2006, Lenk et al. 2007). Therefore, the Mx can also supply a rapid assessment of sugar content. Indeed, a first good correlation between the CHL Mx index and total soluble sugar in the cultivars Pinot Noir, Pinot Meunier and Chardonnay has been found (Ben Ghozlen et al. 2010a).

Optical non-destructive sensors, such as that used in the present work, appear to be well suited as tools for integration in grapevine management practices facing the influence of global climate change on fruit quality and production (Keller 2010).
The cv. Aleatico proved to be tolerant to WS conditions, as preliminarily observed in potted plants (unpublished data), allowing its cultivation in territories where irrigation is not available.

\section{Acknowledgements}

The authors are grateful to Bulichella winery for hosting the trials. This work was supported in part by the Italian CNR through the 'Ricerca Spontanea a Tema Libero' grant and by the Foundation 'Cassa di Risparmi di Livorno' and 'PRIN 08'. We thank Zoran Cerovic at CNRS-Université Paris-Sud and two anonymous reviewers for their useful critical comments on the manuscript.

\section{References}

Acevedo, C.O., Ortega-Farías, S. and Moreno, Y. (2004) Effect of three levels of water application during post-setting and post-veraison over vegetative development, productivity and grape quality on cv. Cabernet Sauvignon. Acta Horticulturae 646, 143-146.

Agati, G., Meyer, S., Matteini, P. and Cerovic, Z.G. (2007) Assessment of anthocyanins in grape (Vitis vinifera L.) berries using a non-invasive chlorophyll fluorescence method. Journal of Agricultural and Food Chemistry 55, 1053-1061.

Agati, G., Traversi, M.L. and Cerovic, Z.G. (2008) Chlorophyll fluorescence imaging for the non-invasive assessment of anthocyanins in whole grape (Vitis vinifera L.) bunches. Photochemistry and Photobiology 84, 14311434.

Agati, G., Mattii, G., Tuccio, L., Remorini, D., Tonutti, P. and Scalabrelli, G. (2009) Non destructive in vineyard monitoring of winegrape phenolic maturity using a portable fluorescence sensor. 5th International specialized conference on sustainable viticulture: winery waste and ecologic impacts management - Winery 2009, Trento, Italy (Università degli Studi di Trento, Trento: City) pp. 455-458.

Ben Ghozlen, N., Cerovic, Z.G., Germain, C., Toutain, S. and Latouche, G. (2010a) Non-destructive optical monitoring of grape maturation by proximal sensing. Sensors 10, 10040-10068.

Ben Ghozlen, N., Moise, N., Latouche, G., Martinon, V., Mercier, L., Besançon, E. and Cerovic, Z.G. (2010b) Assessment of grapevine maturity using new portable sensor: Non-destructive quantification of anthocyanins. Journal International des Sciences de la Vigne et du Vin 44, 1-8. Bramley, R. (2005) Understanding variability in winegrape production systems. 2. Within vineyard variation in quality over several vintages. Australian Journal of Grape and Wine Research 11, 33-42.

Brouwer, C. and Heibloem, M. (1986) Irrigation water management: irrigation water needs (Food and Agriculture Organization of the United Nations (FAO): Rome, Italy).

Buschmann, C. (2007) Variability and application of the chlorophyll fluorescence emission ratio red/far-red of leaves. Photosynthesis Research $\mathbf{9 2}$, 261-271.

Butz, P., Hofmann, C. and Tauscher, B. (2005) Recent developments in noninvasive techniques for fresh fruit and vegetable internal quality analysis. Journal of Food Science 70, R131-R141.

Castellarin, S.D., Matthews, M.A., Di Gaspero, G. and Gambetta, G.A. (2007a) Water deficits accelerate ripening and induce changes in gene expression regulating flavonoid biosynthesis in grape berries. Planta 227, 101-112.

Castellarin, S.D., Pfeiffer, A., Sivilotti, P., Degan, M., Peterlunger, E. and Di Gaspero, G. (2007b) Transcriptional regulation of anthocyanin biosynthesis in ripening fruits of grapevine under seasonal water deficit. Plant, Cell and Environment 30, 1381-1399.

Cerovic, Z.G., Samson, G., Morales, F., Tremblay, N. and Moya, I. (1999) Ultraviolet-induced fluorescence for plant monitoring: present state and prospects. Agronomie: Agriculture and Environment 19, 543-578.

Cerovic, Z.G., Ounis, A., Cartelat, A., Latouche, G., Goulas, Y., Meyer, S. and Moya, I. (2002) The use of chlorophyll fluorescence excitation spectra for the non-destructive in situ assessment of UV-absorbing compounds in leaves. Plant, Cell and Environment 25, 1663-1676.

Cerovic, Z.G., Moise, N., Agati, G., Latouche, G., Ben Ghozlen, N. and Meyer, S. (2008) New portable optical sensors for the assessment of winegrape phenolic maturity based on berry fluorescence. Journal of Food Composition and Analysis 21, 650-654.

Cerovic, Z.G., Goutouly, J.-P., Hilbert, G., Destrac-Irvine, A., Martinon, V. and Moise, N. (2009) Mapping winegrape quality attributes using portable fluorescence-based sensors. FRUTIC 09, Conception, Chile (Progap INIA, Chillian, Chile: City) pp. 301-310. 
Chalmers, Y.M., Krstic, M.P., Downey, M.O., Dry, P.R. and Loveys, B.R (2008) Impacts of sustained deficit irrigation on quality attributes and flavonoid composition of Shiraz grapes and wine. Acta Horticulturae $\mathbf{7 9 2}$ $163-170$.

Cifre, J., Bota, J., Escalona, J.M., Medrano, H. and Flexas, J. (2005) Physiological tools for irrigation scheduling in grapevine (Vitis vinifera L. An open gate to improve water-use efficiency? Agriculture Ecosystems \& Environment 106, 159-170.

Conde, C., Silva, P., Fontes, N., Dias, A.C.P., Tavares, R.M., Sousa, M.J., Agasse, A., Delrot, S. and Gerós, H. (2007) Biochemical changes throughout grape berry development and fruit and wine quality. Food 1, 1-22.

Davies, K.M., Schwinn, K.E., Deroles, S.C., Manson, D.G., Lewis, D.H. Bloor, S.J. and Bradley, J.M. (2003) Enhancing anthocyanin production by altering competition for substrate between flavonol synthase and dihydroflavonol 4-reductase. Euphytica 131, 259-268.

Deluc, L.G., Quilici, D.R., Decendit, A., Grimplet, J., Wheatley, M.D. Schlauch, K.A., Merillon, J.M., Cushman, J.C. and Cramer, G.R. (2009) Water deficit alters differentially metabolic pathways affecting important flavor and quality traits in grape berries of Cabernet Sauvignon and Chardonnay. BMC Genomics 10, 212-245.

Deluc, L.G., Quilici, D.R., Decendit, A., Grimplet, J., Wheatley, M.D., Schlauch, K.A., Merillon, J.M., Cushman, J.C. and Cramer, G.R. (2009) Water deficit alters differentially metabolic pathways affecting important flavor and quality traits in grape berries of Cabernet Sauvignon and Chardonnay. BMC Genomics 10, 212-245.

Di Stefano, R., Mattivi, F., Caburazzi, M., Giustini, E. and Bonifazi, L. (2008) Evoluzione della composizione fenolica dell'uva Sagrantino durante la maturazione. Rivista di Viticoltura e di Enologia 1, 39-61.

Downey, M.O., Dokoozlian, N.K. and Krstic, M.P. (2006) Cultural practice and environmental impacts on the flavonoid composition of grapes and wine: a review of recent research. American Journal of Enology and Viticulture 57, 257-268.

Downey, M.O., Mazza, M. and Krstic, M.P. (2007) Development of a stable extract for anthocyanins and flavonols from grape skin. American Journal of Enology and Viticulture 58, 358-364.

Düring, H., Loveys, B.R. and Dry, P.R. (1996) Root signals affect water use efficiency and shoot growth. Acta Horticulturae 427, 1-14.

Fregoni, M. (2005) Viticoltura di qualità (Tecniche Nuove: Milano).

Gishen, M., Dambergs, R.G. and Cozzolino, D. (2005) Grape and wine analysis enhancing the power of spectroscopy with chemometrics. A review of some applications in the Australian wine industry. Australian Journal of Grape and Wine Research 11, 296-305.

Hsiao, T.C. (1973) Plant responses to water stress. Annual Review of Plant Physiology 24, 519-570.

Jaakola, L., Määttä-Riihinen, K., Kärenlampi, S. and Hohtola, A. (2004) Activation of flavonoid biosynthesis by solar radiation in bilberry ( $\mathrm{Vac}$ cinium myrtillus L.) leaves. Planta 218, 721-728.

Keller, M. (2010) Managing grapevines to optimise fruit development in a challenging environment: a climate change primer for viticulturists. Australian Journal of Grape and Wine Research 16, 56-69.

Kennedy, J.A., Matthews, M.A. and Waterhouse, A.L. (2002) Effect of maturity and vine water status on grape skin and wine flavonoids. American Journal of Enology and Viticulture 53, 268-274.

Kolb, C.A., Wirth, E., Kaiser, W.M., Meister, A., Riederer, M. and Pfündel, E.E. (2006) Noninvasive evaluation of the degree of ripeness in grape berries (Vitis vinifera L. cv. Bacchus and Silvaner) by chlorophyll fluorescence. Journal of Agricultural and Food Chemistry 54, 299-305.

Le Moigne, M., Symoneaux, R. and Jourjon, F. (2008) How to follow grape maturity for wine professionals with a seasonal judge training? Food Quality and Preference 19, 672-681.

Lenk, S., Buschmann, C. and Pfündel, E.E. (2007) In vivo assessing flavonols in white grape berries (Vitis vinifera L. cv. Pinot Blanc) of differen degrees of ripeness using chlorophyll fluorescence imaging. Functional Plant Biology 34, 1092-1104.

Matthews, M.A. and Anderson, M.M. (1987) Phenologic and growth responses to early and late season water deficits in Cabernet Franc. Vitis 26, 147-160.

Medrano, H., Escalona, J.M., Cifre, J., Bota, J. and Flexas, J. (2003) A ten-year study on the physiology of two Spanish grapevine cultivars under field conditions: effects of water availability from leaf photosynthesis to grape yield and quality. Functional Plant Biology 30, 607-619.

Mulinacci, N., Ieri, F., Giaccherini, C., Innocenti, M., Andrenelli, L., Canova, G., Saracchi, M. and Casiraghi, M.C. (2008) Effect of cooking on the anthocyanins, phenolic acids, glycoalkaloids, and resistant starch content in two pigmented cultivars of Solanum tuberosum L. Journal of Agricultural and Food Chemistry 56, 11830-11837.

Naor, A., Bravdo, B. and Gelobter, J. (1994) Gas-exchange and water relations in field-grown sauvignon blanc grapevines. American Journal of Enology and Viticulture 45, 423-428.

Ojeda, H., Deloire, A. and Carbonneau, A. (2001) Influence of water deficits on grape berry growth. Vitis 40, 141-145.

Ojeda, H., Andary, C., Kraeva, E., Carbonneau, A. and Deloire, A. (2002) Influence of pre- and postvéraison water deficit on synthesis and concentration of skin phenolic compounds during berry growth of Vitis vinifera L., cv Shiraz. American Journal of Enology and Viticulture 53, 261-267.

Peterlunger, E., Castellarin, S.D., Bigot, G., Leon, M., Donda, L., Bucchetti, B., Battistutta, F. and Bregant, F. (2010) Effect of regulated water defici on fruit maturation in red and white grapevine varieties grown in the 'Friuli Isonzo' DOC area. Italus Hortus 17, 134-140.

Poni, S., Lakso, A.N., Turner, J.R. and Melious, R.E. (1993) The effects of pre-véraison and post-véraison water-stress on growth and physiology of potted pinot-noir grapevines at varying crop levels. Vitis 32, 207-214. Remorini, D., Battelli, R., Tuccio, L., Ferroni, G., Massai, R. and Scalabrelli, G. (2010) Applicazione di indicatori fisiologici nella gestione del deficit idrico della vite in pieno campo. Italus Hortus 17, 224-228.

Roby, G. and Matthews, M.A. (2004) Relative proportions of seed, skin and flesh, in ripe berries from Cabernet Sauvignon grapevines grown in a vineyard either well irrigated or under water deficit. Australian Journal of Grape and Wine Research 10, 74-82.

Roby, G., Harbertson, J.F., Adams, D.A. and Matthews, M.A. (2004) Berry size and vine water deficits as factors in winegrape composition: anthocyanins and tannins. Australian Journal of Grape and Wine Research 10, 100-107.

Saracini, E., Tattini, M., Traversi, M.L., Vincieri, F.F. and Pinelli, P. (2005) Simultaneous determination of ellagitannins, flavonoid glycosides and acyl-glycosyl flavonoids in Cistus salvifolius L. leaves by HPLC-DAD and HPLC-MS. Chromatographia 62, 245-249.

Sivilotti, P., Bonetto, C., Paladin, M. and Peterlunger, E. (2005) Effect of soil moisture availability on Merlot: from leaf water potential to grape composition. American Journal of Enology and Viticulture 56, 9-18.

Van Rooyen, P.C., Ellis, L.P. and Du Plessis, C.S. (1984) Interactions between grape maturity indices and quality for Pinotage and Cabernet Sauvignon wines from four localities. South African Journal of Enology and Viticulture 5, 29-34.

Wample, R.L. and Smithyman, R. (2002) Regulated deficit irrigation as a water management strategy in Vitis vinifera production. In: Deficit irrigation practices - FAO water reports. (FAO: Rome, Italy) pp. 89100 .

\section{Manuscript received: 2 September 2010}

Revised manuscript received: 17 December 2010

Accepted: 29 December 2010

\section{Supporting information}

Additional Supporting Information may be found in the online version of this article: http://onlinelibrary.wiley.com/doi/ 10.1111/j.1755-0238.2011.00139.x/abstract

Figure S1. Climatic parameters for the 2008 (a) and 2009 (b) seasons obtained from the Tuscany Regional Agrometeorological Service.

Figure S2. Rainfall and ETo data for the 2008 (a) and 2009 (b) seasons obtained from the Tuscany Regional Agrometeorological Service and calculated according to the BlaneyCriddle's method (Brouwer and Heibloem 1986).

Please note: Wiley-Blackwell are not responsible for the content or functionality of any supporting materials supplied by the authors. Any queries (other than missing material) should be directed to the corresponding author for the article. 